\title{
Postpartum spontaneous vulvar hematoma as a cause of maternal near miss: a case report and review of the literature
}

\author{
Temesgen Tilahun ${ }^{1 *}$, Aaga Wakgari ${ }^{1}$, Aschalew Legesse ${ }^{1}$ and Rut Oljira ${ }^{2}$
}

\begin{abstract}
Background: Postpartum spontaneous vulvar hematoma is a rare complication of childbirth that can potentially cause maternal death if not managed properly and in a timely manner.

Case summary: We present the case of maternal near miss secondary to postpartum hemorrhage secondary to vulvar hematoma after home delivery in a 28-year-old para IV mother from rural Ethiopia. The case was surgically managed under spinal analgesia. The mother and her newborn were discharged on the fourth postprocedure day.

Conclusion: Neglected and inappropriately managed postpartum vulvar hematoma can cause significant maternal morbidity; therefore, timely surgical exploration, ligation of bleeding vessels, and obliteration of dead space can avert severe maternal complications
\end{abstract}

Keywords: Vulvar hematoma, Postpartum, Severe anemia, Maternal near miss

\section{Introduction}

According to the World Health Organization (WHO), maternal near miss (MNM) is defined as "a woman who nearly died but survived a complication that occurred during pregnancy, childbirth or within 42 days of termination of pregnancy" [1]. In Ethiopia, for every woman who dies from pregnancy-related causes, 12-21 others experience maternal near miss (MNM) [1-3]. One of the causes of MNM is postpartum hemorrhage (PPH) [1, $4,5]$. The major causes of PPH are uterine atony, genital tract laceration, retained tissues (placenta and membranes), and coagulopathy $[4,5]$. Vulvar hematoma is among genital tract traumas that cause PPH $[5,6]$.

A vulvar hematoma is a collection of blood in the vulva [6]. The vulva is soft tissue mainly composed of smooth muscle and loose connective tissue and is supplied by

*Correspondence: ttamuko@yahoo.com

1 Department of Obstetrics and Gynecology, Institute of Health Sciences, Wollega University, Oromia, P.O Box: 395, Nekemte, Ethiopia

Full list of author information is available at the end of the article branches of the pudendal artery $[7,8]$. The venous drainage is provided by labial veins, and labial veins drain into the external and internal pudendal veins $[8,9]$. This vulvar vasculature commonly develops varicosities during pregnancy, especially in parous women, due to increased venous pressure created by the increasing weight of the uterus [8]. Damage to labial branches of the internal pudendal artery in this vascular network easily initiates hematoma development [7-9].

Postpartum vulvar hematomas cause maternal morbidities such as anemia, postpartum hemorrhage, superinfection, necrotizing fasciitis, prolonged hospitalization, and need for transfusion [5-7]. Here we present, a case of postpartum vulvar hematoma as the cause of MNM.

\section{Case presentation}

This is a 28-year-old para IV mother from rural Ethiopia who gave birth to an alive female neonate weighing $3000 \mathrm{~g}$ at home 24 hours before presentation. She did not remember her last normal menstrual period (LNMP) but claimed to be amenorrheic for 9 months. She had original author(s) and the source, provide a link to the Creative Commons licence, and indicate if changes were made. The images or other third party material in this article are included in the article's Creative Commons licence, unless indicated otherwise in a credit line to the material. If material is not included in the article's Creative Commons licence and your intended use is not permitted by statutory regulation or exceeds the permitted use, you will need to obtain permission directly from the copyright holder. To view a copy of this licence, visit http://creativecommons.org/licenses/by/4.0/. The Creative Commons Public Domain Dedication waiver (http://creativeco mmons.org/publicdomain/zero/1.0/) applies to the data made available in this article, unless otherwise stated in a credit line to the data. 
antenatal care (ANC) at a nearby health center where she had routine investigations and care during pregnancy. During the last antenatal visit, she was told to come to the health center when she feels labor pains. However, her labor advanced within 6 hours of the onset of labor pain. She gave birth normally at home with the assistance of traditional birth attendants. The mother reported that there was neither difficulty with delivery of the placenta nor excessive bleeding during and after delivery. She noticed gradual swelling of her right vulva that was associated with vulvar pain. Due to the worsening of these complaints, the family took her to nearby hospital. At this hospital, evacuation of vulvar hematoma $(6 \mathrm{~cm} \times 8 \mathrm{~cm})$ was done. The managing team evacuated $500 \mathrm{ml}$ of hematoma and referred the patient to Wollega University Referral Hospital (WURH) for blood transfusion.

Upon arrival to WURH, the patient was re-evaluated by the charge resident physician and consultant gynecologist, and obstetrician. The mother reported vaginal bleeding from the vulva on her way to WURH, significant swelling of the vulva, and vulvar pain. She had difficulty with micturition. She also complained of palpitation, easy fatigability, vertigo, and headache. The patient had no history of hypertension, diabetes mellitus, or bleeding tendency.

On examination, she was acutely sick-looking. Her vital signs were blood pressure (BP) $90 / 60 \mathrm{mmHg}$, pulse rate (PR) 136 beats per minute, respiratory rate (RR) 22 breaths per minute, and temperature $37.1{ }^{\circ} \mathrm{C}$. She had dry buccal mucosa and pale conjunctivae. Lymph glandular system, chest, and cardiovascular system were normal. Abdominal examination showed a 20-weeksized uterus that was well contracted and nontender, and the bladder was distended. There were no signs of fluid collection or organomegaly. On genital examination, there was a $12 \times 20 \mathrm{~cm}$ right-sided vulvar mass extending to the mons pubis and posteriorly to the right buttock (Fig. 1). The mass was tender and fluctuant. There were two stitches applied to it. However, there was bleeding from this site. There was no active vaginal bleeding or vaginal and cervical tear. She exhibited palmar pallor. On neurologic examination, she was oriented to time, person, and place. She had normal reflexes and no neurologic deficits. With the final diagnosis of severe anemia secondary to postpartum hemorrhage secondary to a vulvar hematoma, she was admitted to the obstetric ward. At admission, she was investigated and the results were as indicated in Table 1.

The patient was prepared and taken to the operation room. Under spinal analgesia, through a previous incision made at referring hospital, about $700 \mathrm{ml}$ of clotted blood was evacuated from vulvar hematoma. The actively bleeding vessels were identified and ligated. Then, the

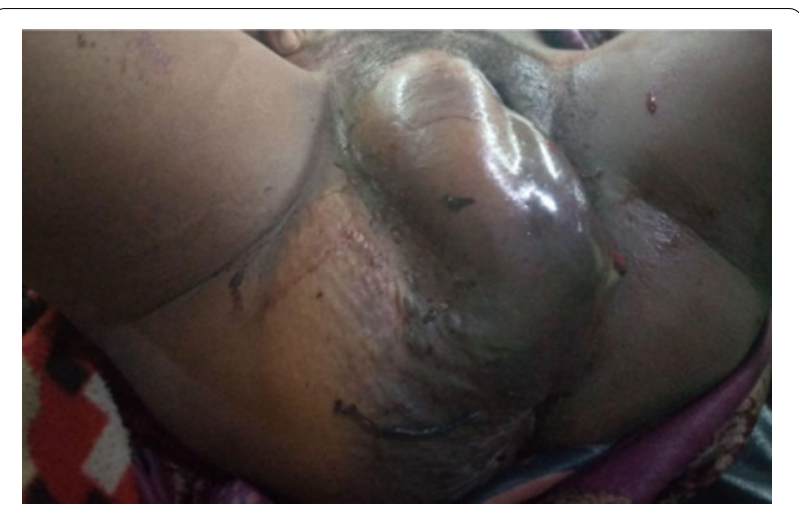

Fig. 1 Postpartum spontaneous vulvar hematoma managed at Wollega University Referral Hospital, Western Ethiopia, 2021

wound was sutured in three layers. The site was observed for bleeding and vulvar swelling. A hemostatic gauze was used for further compression and removed after 12 hours. The patient was transferred to ward where she was transfused with two units of compatible blood. On the fourth postprocedure day, the patient was discharged with ferrous sulfate and appropriate advice on vulvar care.

\section{Discussion}

This is the case of maternal near miss in rural Ethiopia. The major causes of maternal near-miss events are obstetric hemorrhages, hypertensive disorders of pregnancy, difficult labor and delivery, sepsis, complications of abortion, and uterine rupture $[1,5]$. This patient presented with postpartum hemorrhage (PPH) secondary to spontaneous vulvar hematoma. It is an unusual cause of $\mathrm{PPH}[5,6]$. The other causes of PPH such as uterine atony retained tissue, coagulopathy, and genital tract laceration were excluded from patient history, physical examination, and laboratory investigation. A huge postpartum vulvar hematoma explained the patient's condition. The hematoma was severe enough to cause maternal shock and severe anemia. This patient could have died had she not been aggressively managed with intravenous fluid, blood transfusion, and surgical intervention.

Postpartum vulvar hematomas are rare events in modern obstetrics. Their magnitude varies from 1 per 300 to 1 per 15,000 deliveries. It can be classified into obstetric and non-obstetric vulvar hematomas $[6,8,10,11]$. Postpartum vulvar hematomas most frequently result from genital tract laceration [8] or improper hemostasis during the repair of perineal tears or an episiotomy wound. Failure to take precautions while suturing the apex of the episiotomy may result in a large vulvovaginal hematoma due to the distensible nature of the tissue $[12,13]$. 
Table 1 Summary of laboratory investigations of the case of postpartum spontaneous vulvar hematoma managed at Wollega University Referral Hospital, Western Ethiopia, 2021

\begin{tabular}{|c|c|c|}
\hline Time of investigations & Laboratory tests & Results \\
\hline \multirow[t]{7}{*}{ At admission } & CBC count & 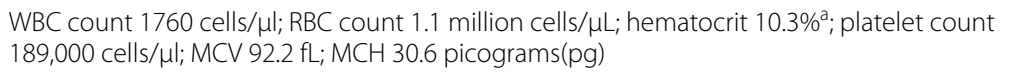 \\
\hline & Urinalysis & Nonrevealing \\
\hline & RBG & $145 \mathrm{mg} / \mathrm{dl}$ \\
\hline & Blood group & $\mathrm{B}+$ \\
\hline & Abdominopelvic ultrasound & Empty uterus, no peritoneal collection \\
\hline & VDRL & Nonreactive \\
\hline & $\mathrm{HBsAg}$ & Nonreactive \\
\hline \multirow[t]{3}{*}{ After procedure } & CBC count & 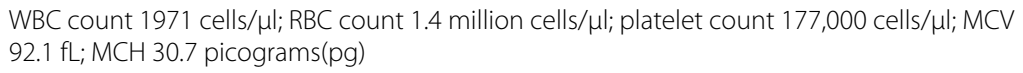 \\
\hline & & Hematocrit $12.9 \%^{\mathrm{b}}$ \\
\hline & & Hematocrit $17.2 \%^{c}$ \\
\hline
\end{tabular}

$C B C$ complete blood count, WBC white blood cell, $R B C$ red blood cell, VDRL Venereal Disease Research Laboratory, HBsAg hepatitis $B$ surface antigen, $R B G$ random blood glucose, $M C V$ mean corpuscular volume, $M C H$ mean corpuscular hemoglobin

${ }^{\text {a }}$ At admission

${ }^{\mathrm{b}}$ After the first transfusion

${ }^{\mathrm{c}}$ After the second transfusion

Postpartum spontaneous vulvar hematomas are rare events. They result from injury to blood vessels in the absence of laceration or incision of the surrounding tissue (such as pseudoaneurysm and traumatic arteriovenous fistula) $[10,13]$. They usually follow precipitate labor, macrosomic babies, prolonged second stage of labor, hypertensive disorders of pregnancy, coagulopathy, or vulvar varicosities $[2,10,11,14]$. In our case, the total duration of labor was only 6 hours, which might have been the triggering factor. It occurred spontaneously after home vaginal delivery. It is observed that most spontaneous vulvar hematomas are right-sided vulvar hematomas [11] as in our case. This may be due to dextrorotation of the uterus, which might cause vulvar varicosities.

The pathogenesis of vulvar hematomas is due to iatrogenic injury to blood vessels and/or spontaneous rupture resulting in various symptoms such as vulvar swelling, vulvar pain, and urologic symptoms $[6,8,10$, 15]. Our patient presented with vulvar swelling, vulvar pain, and difficulty with urination. As bleeding into the vulva is largely restricted only by the Colles fascia and the urogenital diaphragm, a hematoma in this area is visible as tender fluctuant mass [15] as in our case.

Vulvar hematomas may develop within hours after delivery or be initially misdiagnosed as vulva swelling or edema until the delayed formation of the hematoma $[8,14]$. Early recognition is paramount in reducing the associated morbidity, improving patient outcomes, and shortening the length of hospital stay. Delay in recognition and management may result in adverse consequences and increase maternal morbidity $[7,11$, $14]$ as in our case.

The management of vulvar hematomas depends on the size of the hematoma, hemodynamic stability of the patient, availability of medical resources, and duration of the hematoma $[9,10,14,16]$. Smaller and chronic vulvar hematomas can be conservatively managed [9] including the use of sitz baths, ice packs, empiric antibiotics, pain medication, and/or blood transfusion [12, 14]. However, large and rapidly expanding hematomas, as in this case, are managed by surgical techniques $[9,11]$. The surgical management can be surgical exploration or selective arterial embolization [9, 10]. The surgical exploration consists of incision and drainage of the hematoma, ligation of the bleeding vessels, and packing or placement of drainage tube [9-11]. Our patient was managed by a similar approach. However, the primary treating hospital did not place a vaginal pack or drainage tube. As a result, the patient was having ongoing active bleeding from the incision site on the way to the referral hospital. This made the patient develop a recurrent huge hematoma. Therefore, optimal management of vulvar hematomas includes surgical exploration, ligation of bleeding vessels, obliteration of the dead space and placing pack in the vagina, placing drainage tube, or applying pressure over it $[9,10,14]$. The surgical exploration also prevents pressure necrosis of the surrounding tissue and decreases the risk of infection and necrotizing fasciitis $[6,8]$. Sometimes, however, a surgical repair may fail or a recurrent hematoma can be formed, as in our case. In such cases, selective arterial embolization is the treatment of choice $[10,17]$. 


\section{Conclusion}

Neglected and inappropriately managed postpartum vulvar hematoma can cause significant maternal morbidity; therefore, timely surgical exploration, ligation of bleeding vessels, and obliteration of dead space can avert maternal complications

\section{Abbreviations}

ANC: Antenatal care; CBC: Complete blood count; HBsAg: Hepatitis B surface antigen; LNMP: Last normal menstrual period; MCH: Mean corpuscular hemoglobin; MCV: Mean corpuscular volume; MNM: Maternal near miss; PPH: Postpartum hemorrhage; RBC: Red blood cell; RBG: Random blood glucose; VDRL: Venereal Disease Research Laboratory; WBC: White blood cell; WUR: Wollega University Referral Hospital.

\section{Acknowledgments}

We thank the patient for allowing the publication of this case report.

\section{Authors' details}

TT is Associate Professor of obstetrics and gynecology, Institute of Health Sciences, Wollega University; AW is Assistant Professor of obstetrics and gynecology, Institute of Health Sciences, Wollega University; AL is medical doctor and first-year resident of obstetrics and gynecology, Institute of Health Sciences, Wollega University; RO is lecturer in the department of public health, Institute of Health Sciences, Wollega University.

\section{Authors' contributions}

All authors made a significant contribution to the work reported, whether that is in the conception, study design, execution, acquisition of data, analysis, and interpretation, or in all these areas; took part in drafting, revising, or critically reviewing the article; gave final approval of the version to be published; have agreed on the journal to which the article has been submitted; and agree to be accountable for all aspects of the work. All authors read and approved the final manuscript.

\section{Funding}

No funding source

\section{Availability of data and materials}

The datasets used during the current study are available from the corresponding author on reasonable request.

\section{Declarations}

Ethics approval and consent to participate

Wollega University Referral Hospital has approved the publication of this case. The study protocol is performed per the relevant guidelines.

\section{Consent for publication}

Written informed consent was obtained from the patient for publication of this case report and any accompanying images. A copy of the written consent is available for review by the Editor-in-Chief of this journal.

\section{Competing interests}

The authors report no competing interests.

\section{Author details}

${ }^{1}$ Department of Obstetrics and Gynecology, Institute of Health Sciences, Wollega University, Oromia, P.O Box: 395, Nekemte, Ethiopia. ${ }^{2}$ Department of Public Health, Institute of Health Sciences, Wollega University, Nekemte, Ethiopia.

Received: 23 November 2021 Accepted: 20 January 2022

Published online: 28 February 2022

\section{References}

1. World Health Organization. Evaluating the quality of care for severe pregnancy complications: the WHO near-miss approach for maternal health. 2011.

2. Gebrehiwot $Y$, Tewolde BT. Improving maternity care in Ethiopia through facility-based review of maternal deaths and near misses. Int J Gynecol Obstet. 2014;127:S29-34.

3. Tura AK, Zwart J, van Roosmalen J, Stekelenburg J, van den Akker T, Scherjon S. Severe maternal outcomes in eastern Ethiopia: application of the adapted maternal near miss tool. PLoS ONE. 2018;13(11):e0207350.

4. Wormer KC, Jamil RT, Bryant SB. Acute Postpartum Hemorrhage. [Updated 2021 Jul 26]. In: StatPearls [Internet]. Treasure Island (FL): StatPearls Publishing; 2021 Jan. Available from: https://www.ncbi.nlm.nih. gov/books/NBK499988/.

5. Anass E et al. Post-partum hemorrhagic shock following puerperal hematoma. PAMJ Clin Med. 2020;3(43). https://doi.org/10.11604/pamj-cm. 2020.3.43.2310.

6. Oong GC, Eruo FU. Vulvar Hematoma. [Updated 2021 Aug 14]. In: StatPearls [Internet]. Treasure Island (FL): StatPearls Publishing; 2021. Available from: https://www.ncbi.nlm.nih.gov/books/NBK560753/.

7. Mangwi AA, Ebasone PV, Aroke D, Ngek LT, Nji AS. Non-obstetric vulva hematomas in a low resource setting: two case reports. Pan Afr Med J. 2019;33:314.

8. Hong HR, Hwang KR, Kim SA, et al. A case of vulvar hematoma with rupture of pseudoaneurysm of a pudendal artery. Obstet Gynecol Sci. 2014;57(2):168-71. https://doi.org/10.5468/ogs.2014.57.2.168.

9. Gulbasi C, et al. Surgical management and clinical follow-up of post-coital severe vulvar hematoma in a 14-year-old adolescent girl: a case presentation. Acta Biomed. 2021;92(Supplement 1):e2021041.

10. Shivhare $S$, et al. Endovascular management of episiotomy site hematoma. Turk J Obstet Gynecol. 2021;18:163-6.

11. Gurtovaya Y, Hanna H, Wagley A. Spontaneous intrapartum vulvar hematoma. Midwives. 2013;16(5):48-9.

12. Orugbom Ndu-Akinla C, Paul Dienye N, Owajionyi Dienye P. Vulvovaginal haematoma presenting in the puerperium: a case report. GSC Adv Res Rev. 2021;06(03):083-6.

13. Nagayama C, Gibo M, Nitta H, Uezato T, Hirakawa M, Masamoto H, et al. Rupture of pseudoaneurysm after vaginal delivery successfully treated by selective arterial embolization. Arch Gynecol Obstet. 2011;283:37-40.

14. Tseng JY, Lin IC, Lin JH, Chang CM, Chao WT, Wang PH. The optimal approach for management of postpartum vulva hematoma: report of three cases. Taiwan J Obstet Gynecol. 2020;59(5):780-3. https://doi.org/ 10.1016/j.tjog.2020.07.030 (PMID: 32917338).

15. Egan E, Dundee P, Lawrentschuk N. Vulvar hematoma secondary to spontaneous rupture of the internal iliac artery: a clinical review. Am J Obstet Gynecol. 2009;200(1):e17-8.

16. Benrubi G, Neuman C, Nuss RC, Thompson RJ. Vulvar and vaginal hematomas: a retrospective study of conservative versus operative management. South Med J. 1987;80(8):991-4. https://doi.org/10.1097/00007 611-198708000-00014 (PMID: 3616729).

17. Villella J, Garry D, Levine G, Glanz S, Figueroa R, Maulik D. Postpartum angiographic embolization for vulvovaginal hematoma. A report of two cases. J Reprod Med. 2001;46(1):65-7.

\section{Publisher's Note}

Springer Nature remains neutral with regard to jurisdictional claims in published maps and institutional affiliations. 